\title{
Os efeitos da expatriação sobre a identidade: estudo de caso
}

\author{
The effects of expatriation on identity: case study
}

\author{
Juan Miguel Rosa González \\ José Arimatés de Oliveira²
}

\section{Resumo}

São apresentados depoimentos obtidos por meio de entrevistas semiestruturadas, com indivíduos que vivenciam atualmente ou vivenciaram no passado experiências de expatriação - depois de realizada a devida revisão de literatura. O objetivo principal é identificar nesses relatos a ocorrência de transformações, como consequência da expatriação, na identidade dos sujeitos; para o que foi tomado como marco teórico o conceito de self-shock (choque do eu) de Zaharna (1989). O estudo visa a também identificar nas experiências dos entrevistados a ocorrência de padrões de adaptação à cultura de destino propostos pela literatura clássica sobre expatriação. A análise dos resultados sugere a existência de sustentação empírica para a hipótese do self-shock. Contrariamente, na maioria dos relatos não foram identificadas experiências condizentes com os pressupostos centrais da teoria clássica sobre o processo de adaptação do expatriado.

Palavras-chave: Expatriação. Adaptação. Choque cultural. Choque do eu. Identidade.

\begin{abstract}
The text focuses effects of expatriation experiences on individuals. After a review of literature on the subject, the paper introduces testimonies of individuals who are currently living, or lived in the past, expatriation experiences, obtained through semi-structured interviews. The main objective of the work is to recognize in those reports the occurrence of identity transformations on individuals due to the expatriation experience, taking Zaharna's concept of self-shock (1989) as theoretical framework. The paper also aims to identify in expatriates' experiences patterns of adjustment to host culture proponed by classic expatriation literature. The analysis of results indicates the existence of empirical support for the self-shock hypothesis, while most of expatriates did not report experiences befitting central assumptions of classic theory on expatriates' adjustment process.
\end{abstract}

Keywords: Expatriation. Adjustment. Culture shock. Self-shock. Identity.

Artigo submetido em 09 de fevereiro de 2011 e aceito para publicação em 06 de maio de 2011.

1 Mestrando do Programa de Pós-Graduação em Administração (PPGA) da Universidade Federal do Rio Grande do Norte (UFRN); Graduado em Jornalismo pela Universidade Autônoma de Barcelona (UAB - Espanha). Endereço: Rua Padre Fernandes, 1, CEP 59150-140, Nova Parnamirim, Parnamirim - RN. E-mail: imrosag@yahoo.es

2 Pós Doutor pela Universidade de Barcelona (Espanha); Doutor em Administração de Empresas pela Escola de Administração de Empresas de São Paulo - FGV; Professor Associado da Universidade Federal do Rio Grande do Norte (UFRN). Endereço: Rua Luciano Saldanha, 1825, CEP 59078-390, Capim Macio, Natal - RN. E-mail: arimates@gmail.com 


\section{Introdução}

A literatura de management realiza uma distinção entre os termos expatriado e imigrante: o primeiro aplicase geralmente a profissionais enviados ao exterior por suas empresas; o segundo, a pessoas que deixam os seus países por causas econômicas. Mas o fenômeno da expatriação, entendido pela sua raiz etimológica latina (ex patria, "fora da pátria"), afeta a todos os indivíduos que residem temporária ou permanentemente em um país diferente daquele onde nasceram. É dessa forma que o termo expatriado será usado ao longo do presente estudo.

Entre os múltiplos efeitos da globalização econômica, emerge como um dos mais evidentes o aumento do número de pessoas que deixaram o seu lugar de origem para residir em outro país durante as últimas décadas - seja por tempo determinado ou com caráter indefinido. Conforme dados publicados pelas Nações Unidas no relatório Trends in Total Migration Stock, o número total de expatriados no mundo passou de pouco mais de 81 milhões, em 1970, para mais de 195 milhões, em 2005, e as projeções da instituição indicam que esse número deve ter atingido 214 milhões de indivíduos ao longo de 2010. Atentando-se somente para o coletivo dos profissionais expatriados temporariamente pelas suas empresas, a tendência observável não é diferente: a última pesquisa global sobre expatriação da consultora Mercer (Mercer's Benefits Survey for Expatriates and Globally Mobile Employees), realizada em 2008 junto a 243 empresas multinacionais, indica que o número de profissionais expatriados por essas companhias praticamente dobrou num período de três anos, passando de 50.000, em 2005, para mais de 94.000 em 2008.

A literatura acadêmica tem se debruçado sobre o fenômeno da expatriação desde a segunda metade do século XX, com foco sobre o processo de adaptação dos expatriados aos países de destino. Nessa linha de estudo, deu-se muita atenção à influência de variáveis externas à vida psicológica do indivíduo, tais como a distância entre a cultura de origem e a de destino (BLACK e MENDENHALL, 1991), o papel das redes sociais no país de acolhida (WANG, 2002) ou a fluência do expatriado na língua local (SHAFFER, HARRISON e GILLEY, 1999).

Paralelamente a essa procura por variáveis externas passíveis de facilitar ou obstaculizar o ajuste social e cultural do expatriado, foram propostos modelos lineares para a descrição cronológica das fases que integrariam um processo padrão de adaptação. Um desses modelos - adotado por diversos autores, mas também muito questionado - foi a teoria da curva em U (U-Curve Theory of Adjustment - UCT), desenvolvida inicialmente baseando-se nos estudos de Lysgaard (1955) sobre 200 estudantes noruegueses nos Estados Unidos. Apresentava o processo de adaptação dividido em quatro estágios: fascínio inicial pela nova cultura; posteriormente, choque cultural; e uma prolongada fase de ajuste que levaria o expatriado a alcançar, finalmente, o domínio do novo ambiente.

Na revisão histórica da literatura percebe-se, no entanto, uma lacuna que só recentemente começou a ser preenchida: a análise das transformações que o processo de expatriação provoca na autoimagem do indivíduo, na sua identidade, e os efeitos que esse processo de desconstrução-reconstrução do eu teriam sobre a adaptação ao país de destino e posterior readaptação ao país de origem. Vale salientar que essa transformação profunda do eu vai além das simples mudanças de caráter ou comportamento, afetando os valores centrais do indivíduo e o seu autoconceito.

Mediante uma revisão da literatura sobre expatriação, toma-se como base, no presente estudo, o conceito de self-shock ou "choque do eu" citado por Zaharna (1989) e as diferentes visões acadêmicas dos efeitos da expatriação sobre a identidade do indivíduo. A pesquisa qualitativa é utilizada com sujeitos que vivenciaram ou vivenciam ainda hoje experiências de expatriação, com o objetivo principal de identificar nos seus relatos a proeminência do referido processo de desconstrução-reconstrução da identidade, visando melhor compreendê-lo. $\mathrm{O}$ estudo propõe-se também a identificar nos depoimentos a presença de um padrão de adaptação à cultura de destino que possa suportar a tradicional teoria da curva em $U$ ou reforçar as críticas a ela dirigidas. Para tanto, foram realizados estudos de caso, por meio de entrevistas semiestruturadas, com 
indivíduos de nacionalidades diversas e com dilatadas experiências de expatriação, a maioria dos quais ainda reside no exterior. Uma vez apresentados os resultados das entrevistas e as considerações finais do trabalho, sugerem-se linhas de pesquisa que permitirão uma compreensão mais profunda do objeto de estudo, isto é, o processo de reconfiguração da própria identidade em indivíduos sujeitos a um processo de expatriação.

\section{O processo de adaptação e a teoria da u-curve}

Como salientaram Black e Mendenhall (1991), a maioria dos estudos sobre o processo de adaptação dos expatriados tem se fundamentado na teoria da U-curve, inicialmente descrita por Lysgaard (1955). O embrião desse marco teórico começou a se desenvolver quando o conceito de choque cultural foi cunhado em 1951 pela antropóloga Cora DuBois (apud OBERG, 1954) para descrever as sensações do indivíduo perante a perda das referências da própria cultura e a subsequente dificuldade em atribuir significados aos estímulos de uma cultura diferente e desconhecida. $\mathrm{O}$ conceito, sistematizado pelo também antropólogo Kalervo Oberg, em 1954, passaria a ter um papel central na teoria da $U$-curve, que descreve quatro estágios principais no processo de adaptação (Figura 1): lua-de-mel (honeymoon stage), choque cultural (culture shock stage), ajuste (adjustment stage) e domínio (mastery stage). A teoria da curva em U recebeu uma extensão quando Gullahorn e Gullahorn (1963) desenvolveram a curva em W, que inclui no seu escopo o fenômeno da repatriação.

Figura 1

\section{A Curva em U de adaptação do expatriado}

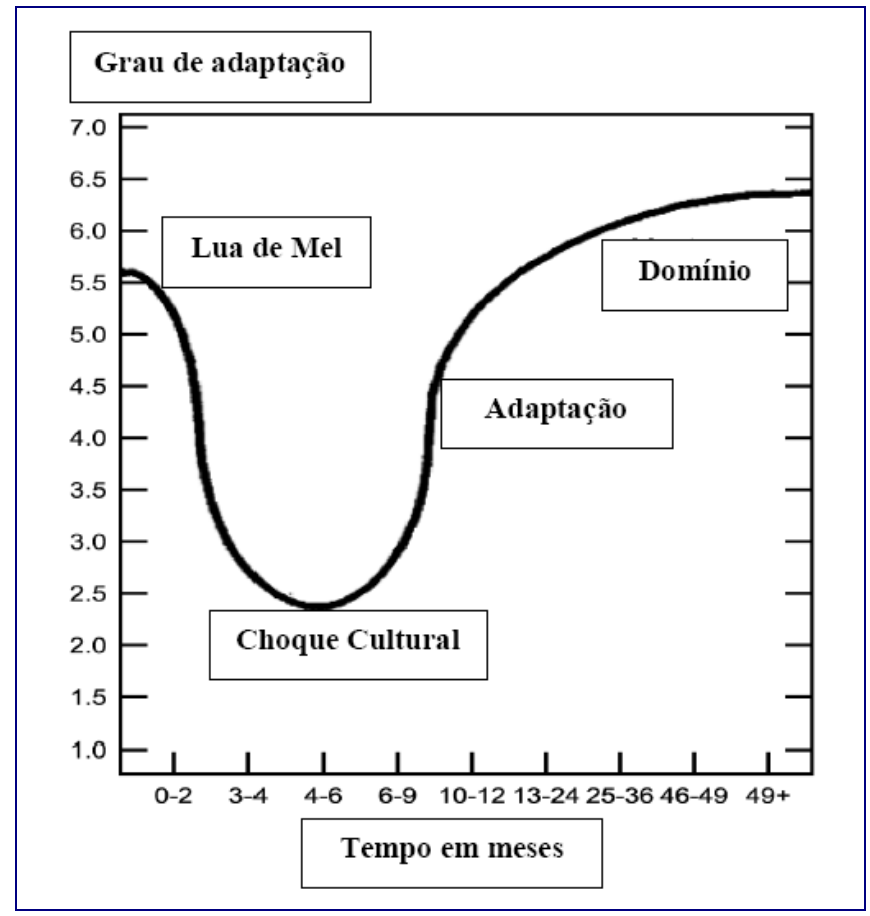

Fonte: Black e Mendenhall (1991, p. 227, tradução nossa)

O estágio inicial que Lysgaard e Oberg identificaram como lua de mel, e que Joly chamaria mais tarde "fase de encantamento" (JOLY, 1996, p. 93), caracteriza-se pelo fascínio e a excitação que a cultura hóspede, com seus "novos e interessantes sons e visões" (BLACK e MENDENHALL, 1991, p. 226) exerce no recém- 
chegado. Para Joly, o fascínio deriva em grande parte do desafio intelectual que o país de acolhida supõe para o expatriado. Essa fase de encantamento, que segundo Oberg poderia durar, dependendo das circunstâncias, desde uns poucos dias até seis meses, começa a se esvaecer na medida em que o indivíduo encontra as primeiras dificuldades para se conduzir no novo ambiente e encaminha-se ao estágio de choque cultural. Oberg explicou esse processo em palestra ministrada no Rio de Janeiro (OBERG, 1954, tradução nossa):

Durante as primeiras semanas, a maioria dos indivíduos fascina-se com o novo. [...] Mas essa mentalidade não sobrevive muito tempo se o sujeito permanece no estrangeiro e tem que lidar seriamente com as condições reais de vida ali. [...] O choque cultural é causado pela ansiedade resultante de perder todos os nossos sinais e símbolos familiares de interrelação social. Estes sinais incluem as mil e uma formas pelas quais nos orientamos com base nas situações da vida quotidiana. [...] Quando o indivíduo adentra uma nova cultura, dele se retira a maioria dessas dicas de interpretação, senão todas. É como um peixe fora da água. [...] Uma série de suportes tem sido retirados dos pés do indivíduo, que sente frustração e ansiedade.

Se o expatriado consegue superar essa fase traumática sem renunciar ao seu projeto de vida no exterior, terá início, conforme a teoria da $U$-Curve, um período de ajuste por meio do qual o indivíduo irá gradativamente adquirindo novas bases de interpretação da realidade e novos padrões de comportamento, até alcançar um domínio suficiente do ambiente.

\section{Críticas à teoria da U-curve}

Diversos autores questionaram, em primeiro lugar, a inevitabilidade da fase de lua de mel, propondo que, em virtude de múltiplas variáveis individuais e externas, os processos de adaptação poderiam apresentar uma forma de curva em J, com maiores dificuldades de adaptação no começo. Essa possibilidade, proposta, entre outros, por Black e Mendenhall (1991), foi significativamente reforçada pela pesquisa longitudinal - uma das poucas dessa natureza nos estudos com expatriados - conduzida por Ward, Okura, Kennedy et al. (1998), com 35 estudantes japoneses na Nova Zelândia. Neste trabalho, constatou-se que as maiores dificuldades de adaptação produziram-se imediatamente depois da chegada dos expatriados ao país de destino, diminuindo com o decorrer do tempo.

As conotações negativas do conceito de choque cultural, que Oberg descreveu como "uma doença ocupacional dos expatriados [...] com a sua própria etiologia, sintomas e cura" (OBERG, 1954, tradução nossa) foram também questionadas. Adler (apud HASLBERGER, 2005, p. 162, tradução nossa) entende o choque cultural como "uma profunda experiência de aprendizado que conduz a um alto grau de autoconsciência e crescimento pessoal, [...] uma experiência de autoentendimento e mudança". Ellingsworth (apud HASLBERGER, 2005, p. 162, tradução nossa) afirma que a adaptação envolve "não só confrontar o outro, mas confrontar também o eu". Berry $(1997,2005)$, por sua vez, propõe substituir o termo de choque cultural pelo de estresse de aculturação, lembrando que o conceito de estresse pode ter tanto um caráter positivo (eustress) quanto negativo (distress), característica que o qualifica para melhor capturar a multiplicidade de sensações experimentadas pelos indivíduos durante o processo de aculturação. 


\section{Adaptação cultural: a identidade entra em cena}

Berry descreve o processo de aculturação como a transformação cultural e psicológica que resulta do contato entre dois ou mais grupos culturais e seus membros individuais. Para Berry, o indivíduo dispõe de quatro possíveis estratégias para abordar esse processo: integração, separação, assimilação ou marginalização. Do seu grau de interesse em manter a sua herança cultural original e do seu grau de interesse em adotar a cultura de destino, resulta o predomínio de uma dessas estratégias de aculturação. Assim, pode haver: a) integração, quando há um interesse similar tanto na conservação da cultura de origem quanto na adoção da cultura hóspede; b) separação, quando o interesse na conservação da própria cultura se acompanha de uma rejeição da cultura hóspede; c) assimilação, quando não há interesse em conservar a cultura de origem e sim em adotar a cultura hóspede; e d) marginalização, quando o indivíduo não deseja nem manter a sua cultura original nem adotar a do país de acolhida (BERRY, 1997).

Encontram-se similitudes com o modelo de Berry na proposta de Sánchez, Spector e Cooper (2000), para os quais uma adaptação bem sucedida implica uma identificação a meio caminho entre a cultura originária e a cultura hóspede. Os diferentes graus de identificação com as duas culturas configuram um modelo de adaptação (Figura 2) que incorpora o conceito de estresse e prevê quatro possíveis padrões de identificação cultural do expatriado: não aculturado ao país hóspede; alienado de ambas as culturas (própria e hóspede); reaculturado ao país hóspede; e bicultural, sendo esta última alternativa a única que garantiria baixos níveis de estresse para o expatriado.

Figura 2

\section{Modelo de identificação cultural do expatriado e estresse}

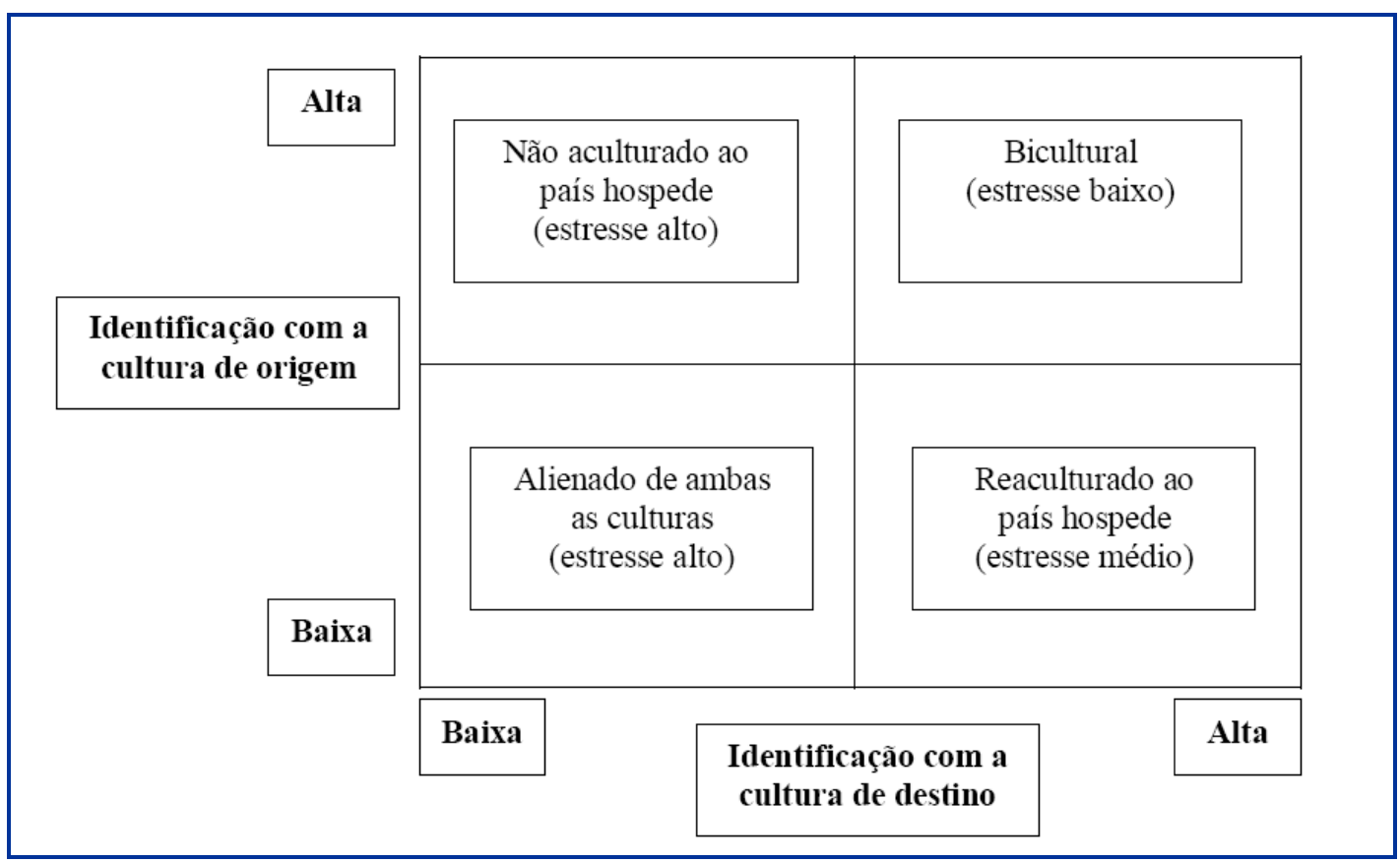

Fonte: Sánchez, Spector e Cooper (2000, p. 101, tradução nossa)

Outro modelo de adaptação cultural foi proposto em 1995 por Kim, para quem o expatriado inevitavelmente atravessa um processo de aculturação-deculturação pelo aprendizado de novas expectativas culturais e o abandono de antigos padrões, processo que se traduz em uma dinâmica de estresse-adaptação-crescimento (KIM, 1995). 
O modelo de Kim introduz, marcantemente, o conceito de crescimento e transformação pessoal, mas talvez seja Sussman quem contribua de forma mais determinante à compreensão do fenômeno de desconstruçãoreconstrução identitária, com o seu Modelo de Identidade Cultural (Cultural Identity Model - CIM). O modelo baseia-se em quatro pressupostos principais (SUSSMAN, 2002, p. 394, tradução nossa):

Primeiro, a identidade cultural é um aspecto crítico, porém latente, do autoconceito; segundo, a saliência da identidade cultural é em grande parte consequência do início de uma transição cultural; terceiro, a identidade cultural é dinâmica e pode mudar como consequência de um processo de expatriação e distúrbios no autoconceito; quarto, mudanças na identidade cultural atuam como mediadores entre a adaptação cultural e a experiência de repatriação.

O modelo de Sussman sugere quatro tipos de identidade pós-adaptação que afetarão significativamente o momento do retorno ao país de origem. Tem-se, em primeiro lugar, a identidade afirmativa, proeminente quando a experiência da expatriação reafirma o indivíduo na sua cultura de origem, dificultando a adaptação ao país de destino, porém facilitando uma experiência positiva de repatriação. A identidade subtrativa, ao contrário, caracteriza-se quando o expatriado se sente menos ligado à sua cultura original, o que faz da repatriação uma experiência traumática. Sussman fala em identidade cultural aditiva quando há um ganho identitário pela adoção de muitos aspectos culturais da cultura hóspede, adoção suficientemente intensa para também dificultar o processo de repatriação. Finalmente, a identidade global é característica de indivíduos com um longo currículo de experiências internacionais. Para eles, o movimento constante entre diferentes culturas só reforça o sentimento de pertencer a uma comunidade global e a hora da repatriação não lhes apresenta grandes dificuldades (SUSSMAN, 2002).

\section{Self-shock ou choque do eu: além da identidade cultural}

Observa-se que a preocupação com a identidade cultural do indivíduo ampliou o seu espaço, durante os últimos anos, nos estudos sobre expatriação, que inicialmente estiveram muito mais concentrados em analisar como o aprendizado de novos comportamentos e formas de interação social no país hóspede poderia contribuir para um melhor desempenho profissional do executivo em missão internacional. Como salienta Grushina (2009), outros prognosticadores da adaptação podem não ser aplicáveis a todos os indivíduos, mas alguma forma de mudança de identidade aparece como necessária e inevitável em qualquer indivíduo confrontado com um novo ambiente, independentemente do seu país de origem.

No entanto, a inclusão da identidade cultural no escopo dos estudos sobre expatriação pode não ser suficiente para entender as transformações profundas do eu associadas a esse processo, desde o momento em que essa identidade cultural é unicamente um aspecto do autoconceito, e não a sua totalidade (SUSSMAN, 2002). O presente estudo propõe que a pergunta mais crítica - e potencialmente desestabilizadora - que o expatriado pode se formular não é "como devo interpretar os comportamentos das pessoas neste país?" nem "sinto-me pertencendo mais a esta nova cultura ou à minha cultura originária?", e sim “quem sou eu aqui?". É nessa indefinição do eu, nessa qualidade subitamente difusa da autoimagem, em que está, acredita-se, a maior fonte de ansiedade para o expatriado. Após certo tempo fora do seu ambiente, extirpado da rede social que lhe dava significado, o indivíduo percebe que não é mais quem era, sem ainda ter uma percepção minimamente sólida de quem passou a ser.

Como apontou Hegde (apud DAI, 2009), a noção de que a identidade é dada, fixa e não contextual foi há muito rejeitada, e hoje é comumente aceito que ela é negociada, construída e constantemente recriada. Para compreender como isso ocorre, deve-se voltar a atenção para o conceito de alteridade, entendida como a relação entre o eu e o outro (MACHADO, 2004). Visto que é somente pela mediação dos outros que o eu pode refletir sobre si mesmo (JOVCHELOVITCH, 1998), esse processo resulta comprometido quando o 
outro é um estranho, quando não temos referências suficientes para decodificar as mensagens mediante as quais ele nos atribui significados e nos diz quem nós somos. Aceitando que a identidade é o senso da realidade do eu dentro da realidade social (ERIKSON, 1968), entende-se que essa realidade do eu, sua existência, pode se ver ameaçada durante o processo de expatriação. Como afirmou o sociólogo Charles Horton Cooley, o indivíduo usa as respostas dos outros para formar imagens de si mesmo (COOLEY, 1924), de maneira que se enxerga como pensa que os outros o veem (ROSENBERG e KAPLAN, 1982). Não menos importante é o papel que a observação do próprio comportamento tem na construção da identidade, como foi apontado por Bern (1972) ao descrever o processo de autoatribuição, por meio do qual o indivíduo descobre as suas próprias atitudes e emoções, parcialmente inferindo-as da observação de seu comportamento ou das circunstâncias em que esse comportamento ocorre. Resulta evidente, assim, que no expatriado pode originarse forte ansiedade identitária por entrar em um processo em que, além de desenvolver permanentemente novos comportamentos, depara-se repetidamente com um outro que não entende, porque carece dos códigos necessários para lê-lo.

Essa ansiedade identitária foi resumida no conceito de self-shock ou 'choque do eu' por Zaharna (1989), para quem as raízes do fenômeno se encontram na relação íntima entre o eu, o outro e os comportamentos. A autora descreve assim esse choque identitário (ZAHARNA, 1989, p. 511, tradução nossa):

Trata-se da intrusão de novas e, às vezes, conflitantes autoidentidades que o indivíduo encontra quando se depara com um Outro culturalmente diferente. As relações conturbadas com o Outro e as ambiguidades comportamentais filtram-se, em última instância, em uma relação conturbada com o eu. Essas relações difíceis afetam a capacidade do indivíduo de se apoiar em autoidentidades reconhecíveis e consistentes. A sensação de "coisa errada" não é mais sobre ambiguidades com o Outro ou ambiguidades comportamentais, e sim sobre ambiguidades com o eu.

Zaharna estabelece três dimensões mediante as quais é possível observar a evolução do processo. A primeira, identificada como perda de competências comunicativas com o eu, caracteriza-se pela incapacidade do indivíduo de reconhecer nos seus próprios comportamentos expectativas a respeito de si. Isto é, os novos comportamentos que adota para se adequar ao ambiente não mais lhe servem para manter uma identidade reconhecível, resultando em perda de autoconfiança e sentimentos de dúvida sobre quem ele é, ou está começando a ser.

Tem-se, em segundo lugar, que as respostas dos outros, longe de colocar luz sobre quem o indivíduo é, acrescentam mais confusão e distorção à sua imagem. Porque, como se viu anteriormente, falta ao expatriado o conhecimento suficiente para adotar a perspectiva do outro - que não é culturalmente semelhante -, o que aumenta significativamente a natural margem de incerteza na hora de decodificar as suas mensagens. Finalmente, a mudança constante de comportamentos leva a uma perda de consistência na relação entre identidade e comportamento, um dos pilares que sustentam o autoconceito.

Zaharna resume o paradoxo do expatriado chamando a atenção para um duplo processo: a falta de significados compartilhados com o outro para os comportamentos aumenta a necessidade que o expatriado sente de confirmar a sua identidade, ao mesmo tempo em que essa ausência de significados compartilhados diminui a capacidade do expatriado de confirmar a sua identidade: “(...) em um momento em que estamos procurando significado fora, nosso eixo interno para a criação de significados é tirado do lugar; a nossa frustração não vem tanto de tentar que o outro faça sentido como de tentar que o eu o faça" (ZAHARNA, 1989, p. 518, tradução nossa). 


\section{Memórias de expatriados}

Os indivíduos que fazem parte do presente estudo compartem, como principal característica, a longa duração das suas experiências de expatriação, que, na maioria dos casos, prolongam-se na atualidade, sem previsão de retorno aos seus países de origem. Convivem na amostra, como se observa na Tabela 1 , nacionalidades e profissões diversas, sendo oportuno salientar que, em nenhum dos casos, a iniciativa da expatriação foi da empresa que na época empregava o indivíduo expatriado. Todos os entrevistados tomaram decisões espontâneas e sustentadas em uma complexa combinação de motivações da qual destaca, como fio condutor, a vontade de mudança.

Vale salientar que a identidade dos indivíduos entrevistados foi preservada para respeitar a sua privacidade, e por ser esse um dado que não acrescenta informações relevantes para o estudo. As sete pessoas entrevistadas são identificadas apenas como 'expats', lançando mão da expressão coloquial usada no jargão corporativo inglês para se referir aos profissionais expatriados.

Tabela 1

Características da amostra

\begin{tabular}{|c|c|c|c|c|c|c|}
\hline Identificação & Sexo & Idade & Profissão & $\begin{array}{l}\text { País de } \\
\text { origem }\end{array}$ & $\begin{array}{l}\text { País de } \\
\text { destino }\end{array}$ & $\begin{array}{l}\text { Período da } \\
\text { expatriação }\end{array}$ \\
\hline Expat 1 & Homem & 37 & Empresário & França & Espanha & $\begin{array}{l}2001 \text { - } \\
\text { atualidade }\end{array}$ \\
\hline Expat 2 & Homem & 34 & Engenheiro & França & Espanha & $2002-2007$ \\
\hline Expat 3 & Homem & 33 & Arquiteto & México & Espanha & $\begin{array}{l}2000- \\
\text { atualidade }\end{array}$ \\
\hline Expat 4 & Mulher & 34 & Administradora & Argentina & Espanha & $2000-2007$ \\
\hline Expat 5 & Mulher & 37 & Empresária & Argentina & Brasil & $\begin{array}{c}1994- \\
\text { atualidade }\end{array}$ \\
\hline Expat 6 & Mulher & 29 & Administradora & Brasil & EUA & $\begin{array}{l}2000- \\
\text { atualidade }\end{array}$ \\
\hline Expat 7 & Mulher & 39 & Empresária & Uruguai & Brasil & $\begin{array}{c}2002- \\
\text { atualidade }\end{array}$ \\
\hline
\end{tabular}

Fonte: Pesquisa de campo. 


\section{Processo de adaptação: $\mathrm{U}, \mathrm{J}$ ou linha gradativamente ascendente?}

Apenas um dos entrevistados reportou, quando solicitado para rememorar as fases iniciais do seu processo de adaptação, sensações ou experiências condizentes com a etapa inicial de lua de mel ou encantamento prevista pela teoria clássica da curva em U. Na maioria dos relatos identificaram-se processos de adaptação gradativa nos quais se observa uma linha suavemente ascendente e sem grandes alterações, como se depreende de alguns testemunhos:

Tendo ascendência e sobrenome catalães, a minha aceitação foi rápida: não era vista como estrangeira e nunca me senti de fora. Meus amigos eram todos catalães e a minha integração foi um processo natural que nunca precisou de grandes esforços. (Expat 4; foi morar em Barcelona, na região da Catalunha, Espanha)

Tive um processo de adaptação muito fácil, conheci pessoas da minha idade num meio muito propício, a universidade, e isso me ajudou a não me encontrar fora de lugar em momento algum. (Expat 3, sobre a sua integração em Barcelona)

Existem ainda casos em que se identifica com facilidade a curva em $\mathbf{J}$ sugerida por Black e Mendenhall (1991) e reforçada empiricamente por Ward, Okura, Kennedy et al. (1998), um padrão que reflete os momentos de maior dificuldade e desconforto psicológico do indivíduo nos primeiros meses da expatriação ou, em alguns casos e dependendo das circunstancias pessoais, nos primeiros anos:

A chegada foi difícil porque fui parar numa pequena cidade litorânea onde estive realmente isolado de tudo, sem contatos, durante cinco meses. Tudo mudou radicalmente quando me mudei para Barcelona. (Expat 2, sobre a sua chegada à Catalunha, Espanha)

Não tive nenhum momento de encantamento. Estava muito mais feliz com o fato de ter tomado a decisão de ir embora do que com o fato mesmo de estar indo. Ou seja, saí chorando de Buenos Aires, continuei chorando por um bom tempo já no Brasil e um belo dia comecei a chorar mais ainda porque percebi que não podia mais sentir aquela falta da minha terra, percebi que teria de esquecê-la para recomeçar. (Expat 5, sobre a sua chegada ao Brasil)

Se houve algum momento bom no início, não durou, no máximo, mais do que vinte dias, porque chegamos com duas crianças depois de eu ter deixado um emprego público no meu país, e meu marido, uma boa posição como professor universitário, confiantes em que uma determinada lei sobre o Mercosul que estava para ser anunciada resolveria a nossa residência no Brasil. Mas a lei não saiu e logo que percebi que as coisas não seriam como eu esperava, entrei literalmente em pânico, tive ataques de pânico e sintomas de depressão, coisa que jamais tinha tido anteriormente. Acabei passando quatro anos na ilegalidade. Foi uma etapa extremamente difícil. (Expat 7, procedente do Uruguai com a família, sobre sua chegada ao Brasil)

A ocorrência de choque cultural no país de destino foi exceção. E onde esse fenômeno foi identificado, não se vislumbra uma ordenação cronológica entre choque cultural e etapa de ajuste, conforme proposto pela teoria da $U$-curve, e sim uma superposição entre profundas divergências culturais e uma gradativa adaptação ao novo cenário vital, uma superposição que perdura, exercendo uma lógica tensão sobre o indivíduo, ao longo dos anos. É o caso exemplificado com claridade no testemunho a seguir:

A diferença cultural é muito grande. Mesmo não vindo de um país muito desenvolvido, como é o Uruguai, o nível cultural de um uruguaio com escolaridade média é muito 
superior ao de um nordestino com o mesmo nível de escolaridade. Tem ainda a falta de compromisso, a falta de formalidade. Até hoje me recuso a me adaptar a essa informalidade, a esse dizer 'estou chegando aí' quando a pessoa nem sequer está vindo, a essa falta de consideração pelo tempo do outro... Por não falar do machismo, que é muito maior aqui. Escuto afirmações que me fazem sentir como se tivesse viajado no túnel do tempo... São diferenças que ainda me fazem sofrer no dia a dia porque são diferenças para trás: menos nível cultural, menos formalidade, menos compromisso, menos respeito pela mulher... Eu sei que não teria direito a criticar uma cultura que estava muito bem sem mim, mas acontece que a critico já como nordestina, porque eu moro e trabalho aqui, estou criando os meus filhos aqui, já sou daqui e isso me dá o direito de apontar as coisas das quais não gosto. (Expat 7)

É importante apreciar que, no relato anterior, não se observa, como fonte principal do desencontro com a cultura de destino, a dificuldade de compreensão dos novos padrões de comportamento - que após sete anos de expatriação são perfeitamente compreendidos pelo indivíduo -, e sim a divergência entre valores e comportamentos socialmente aceitos no país de acolhida com aqueles do expatriado. Não há, neste caso, uma distância cultural a ser transposta pelo aprendizado de novos códigos de comunicação, e sim uma disparidade profunda de princípios, que só poderia mudar se a pessoa atravessasse um processo de transformação da personalidade tão intenso que a levasse a aceitar condutas que até hoje "se recusa" a tolerar.

\section{A visão do outro e a visão de si: a transformação da identidade}

Quase todos os entrevistados referiram-se, em algum momento dos seus depoimentos, com diferentes graus de intensidade, a dimensões relacionadas diretamente com o processo de transformação da identidade, que é objeto central do presente estudo. Como será apontado posteriormente, estudos de natureza longitudinal, com maior grau de aprofundamento na dimensão psicológica da expatriação poderão iluminar melhor um processo que pode se observar nas entrelinhas dos depoimentos a seguir:

Descobri coisas que não sabia de mim. Descobri a minha força, por exemplo. Descobri que podia criar um mundo novo de zero, uma vida nova do nada. (Expat 5)

Eu cresci, a minha cabeça se abriu, mudei muito, sou bem mais madura do que as pessoas que cresceram comigo no Brasil, e também não sou mais a pessoa certinha e regrada que era, mesmo que não deixe a minha família no Brasil perceber plenamente isso, porque quero continuar sendo aceita na cultura deles. (Expat 6, depois de nove anos nos Estados Unidos)

O olhar do outro mudou sim, mas foi porque eu mudei profundamente. Na Argentina eu era vista como uma filhinha de papai, de família tradicional e clássica. E morar em Barcelona transformou a minha personalidade, me fez mais independente, talvez mais fria, ou pelo menos mais forte, menos sensível e, com certeza, muito mais aberta a outras culturas. (Expat 4)

O fato de estar longe do entorno familiar obriga forçosamente a conhecer-se melhor. Há um rompimento com a forma em que você foi educado, você passa a entender que a vida não é necessariamente como você acreditava que era. Sou diferente de quem era, e o que me mudou foi o fato de ter tido de encontrar mecanismos e meios para viver num entorno novo, sozinho, partindo de zero. (Expat 3) 
Somos como esponjas, absorvemos tudo aquilo que vivenciamos e isso muda a nossa forma de ser, modifica a personalidade. Quando você fala em um outro idioma, mesmo sendo fluente nele, você é uma outra pessoa. E quando você fala diversos idiomas, você é uma pessoa diferente em cada um deles. (Expat 1, fluente em três idiomas)

Os relatos anteriores descrevem a transformação identitária como um processo de aprendizado sobre dimensões desconhecidas do próprio eu. Talvez o depoimento que permite apreciar com maior claridade esse processo de transformação da identidade seja este da entrevistada como Expat 7:

O processo de aprendizado não parte de zero, parte de menos mil. É como nascer de novo, você se vê obrigado a demonstrar coisas básicas, como que é uma pessoa honesta e confiável. É uma transformação espiritual, emocional, de estrutura interna, de personalidade. Eu acredito sem sombra de dúvida que sou uma pessoa totalmente diferente da que era no meu país. Os amigos, quando volto ao Uruguai, brincam comigo e eu não me reconheço nessa imagem que eles me transmitem de mim mesma, porque não sou mais essa pessoa. Cada um de nós é sempre uma pessoa e ao mesmo tempo um personagem e eu não reconheço mais o personagem que eu sou para os meus velhos amigos no Uruguai, porque não sou eu. (Expat 7)

Observa-se também, no relato anterior, que um intenso choque cultural e uma profunda mudança de personalidade podem conviver com o ajuste funcional ao novo entorno.

\section{A visão do próprio país e do país de acolhida: qual é o lar do expatriado?}

Somente uma das pessoas entrevistadas - identificada como Expat 4 - voltou ao seu país de origem depois da experiência de expatriação, de forma que não seria procedente analisar, no presente estudo, a ocorrência da curva em W proposta por Gullahorn e Gullahorn (1963) para explicar o processo de expatriaçãorepatriação. Além do que, não se observou, na maioria dos entrevistados, a vivência de um choque cultural, e também não foram relatadas experiências de idealização do país de origem como consequência da falta de adaptação ao país de destino - um dos efeitos colaterais do choque cultural descritos por Oberg (1954). Observa-se, no entanto, em alguns dos entrevistados, uma forte sobrevivência de laços emocionais com a cultura de origem mesmo anos depois de tê-la deixado e de ter aparentemente se adaptado - pelo menos no plano operacional - ao país de destino:

Realmente tenho duas casas: quando estou no Brasil me sinto em casa, mas sempre quero voltar para o meu conforto nos EUA: minha casa, meu carro... Percebo que, se saísse dos Estados Unidos, não sentiria uma falta espiritual, apenas material. Estou mais integrada de uma forma funcional e prática, superficial, não profunda. (Expat 6)

Para entender melhor como uma pessoa que reside nos Estados Unidos há nove anos e que casou com um nativo desse país pode sentir tamanho desapego pela cultura local, é imprescindível atentar para como a entrevistada descreve os norte-americanos:

É difícil saber como as pessoas me veem aqui porque são muito fechadas, difíceis de conhecer, desconfiadas e um tanto superficiais. (Expat 6)

Há mais um exemplo de identidade cultural, e inclusive familiar, conflitante:

Hoje não me identifico nem com a forma de ser dos argentinos nem com a dos brasileiros.

Sinto que não sou como as pessoas de lá nem como as pessoas daqui. Mas, apesar de tudo, 
continuo sentindo-me mais em casa lá. Quando estou com a minha família da Argentina tenho um sentimento forte de que é ali que eu pertenço. Tenho os meus filhos no Brasil e a minha família na Argentina. Nunca entrou na minha cabeça que tenho uma família aqui. Meus filhos podem até ser mais importantes para mim que a minha família argentina, mas, por algum motivo que não entendo, sempre senti que é lá que eu tenho a minha família. (Expat 5, quinze anos depois de ter deixado a Argentina para morar no Brasil, onde teve os seus dois filhos)

Observa-se também que o choque cultural não necessariamente impede o sentir-se em casa no país de acolhida:

Até hoje me questiono se deveria voltar, se ainda poderia construir alguma coisa no meu país... A pergunta me persegue. Mas eu me integrei, não fiquei como simples espectador, com um pé aqui e outro na nostalgia. Hoje a minha casa está aqui. Voltei ao Uruguai aos quatro anos de ter vindo para o Brasil e lá me senti como se fosse uma visita. Quando coloquei os pés de novo no Brasil, senti que tinha chegado em casa. (Expat 7)

Vários depoimentos coincidem, finalmente, quanto à influência da distância sobre o entendimento da própria cultura: "desde fora você entende melhor o seu país"; "você não entende realmente o que significa o seu país, e o que ele significa para você, até sair dele"; "desde fora se tem um olhar mais exato sobre o próprio país"; "aprendemos a amar o nosso país quando estamos fora..." Não é difícil reconhecer por trás desses depoimentos o modelo proposto por Sussman (2002), segundo o qual a saliência da identidade cultural como aspecto central, porém até então latente, do autoconceito só se dá como consequência de uma transição cultural.

\section{Considerações finais e propostas de pesquisa}

Observou-se, nos casos estudados, que diferentes circunstâncias não só pessoais quanto culturais e até geográficas determinaram padrões de adaptação ao país de destino que variam desde uma linha gradativamente ascendente a uma curva em J, com profundas dificuldades iniciais. Só em um dos relatos se identificou a ocorrência da etapa inicial de lua de mel prevista na teoria clássica da Curva em U. O conceito de choque cultural, também identificado somente em um dos casos analisados, não se apresentou na forma descrita pela teoria clássica - a ansiedade resultante de perder todos os sinais e símbolos familiares de interrelaçao social (OBERG, 1954) -, e sim como um desencontro sustentado no tempo entre valores, condutas e comportamentos aceitos na sociedade de destino e os valores e princípios do indivíduo expatriado. O estudo também não encontrou, nas falas dos sujeitos, sinais de idealização do país de origem, um dos efeitos do choque cultural previstos por Oberg. Salienta-se assim que não foram encontradas evidências que sustentem a teoria clássica da Curva em U ou seus pressupostos centrais.

Foi observada, sim, a ocorrência de transformações na identidade e no autoconceito dos sujeitos estudados, transformações que eles mesmos vincularam, sem duvidar, à experiência da expatriação, o que sugere a existência de sustentação empírica para a hipótese do self-shock ou choque do eu proposta por Zaharna (1989). Os entrevistados relataram também experiências condizentes com o processo de aculturação proposto por Berry $(1997,2005)$ e Kim (1995) e com o processo de deconstrução-reconstrução da identidade descrito por Sussman (2002).

Para desentranhar fenômenos de tamanha complexidade seriam necessárias amplas pesquisas qualitativas solidamente apoiadas na psicologia, o que foge ao escopo do presente trabalho. Estudos longitudinais poderão capturar de forma mais exata a cronologia dos acontecimentos mais relevantes durante o processo de adaptação, ao tempo em que pesquisas com expatriados que deixaram o seu país recentemente terão maiores 
chances de sucesso na análise da transição entre a fase de encantamento e a de choque cultural, caso essas fases venham a se manifestar. Parece igualmente aconselhável a realização de pesquisas qualitativas sobre o terreno, por meio das quais os indivíduos estudados possam ser observados no seu contexto real de interação com a cultura de acolhida, de forma que o pesquisador possa produzir o que Geertz define como thick descriptions ou descrições densas (GEERTZ, 1989), capazes de capturar não só os principais fenômenos associados à experiência da expatriação como o contexto em que eles se produzem, permitindo assim uma melhor compreensão dos mesmos.

Com base em alguns depoimentos dos entrevistados sobre o momento da partida - não incluídos aqui por não acrescentarem maiores informações sobre o objeto de estudo -, aponta-se a relevância de pesquisar, como dimensão independente, as motivações dos expatriados que espontaneamente escolhem se aventurar no exterior por motivos que transcendem questões profissionais ou econômicas. Acredita-se que essa linha de pesquisa poderá evidenciar que a expatriação, em não poucas ocasiões, é buscada pelo indivíduo como uma tentativa consciente, porém nem sempre verbalizada, de forçar em si mesmo uma transformação e um crescimento da personalidade.

\section{Referências}

BERN, D. J. Self-Perception Theory. In: BERKOWITZ, L. (Ed.). Advances in Experimental Social Psychology, v. 6 , p. 1-62. New York: Academic Press, 1972.

BERRY, J. W. Immigration, Acculturation, and Adaptation. Applied Psychology: an International Review, v. 46, n. 1, p. 5-68, 1997.

Acculturation: Living successfully in two cultures. International Journal of Intercultural Relations, v. 29, p. 697-712, 2005.

BLACK, J. S.; MENDENHALL, M. The U-Curve adjustment hypothesis revisited: A review and theoretical framework. Journal of International Business Studies, v. 22, n. 2, p. 225-247, 1991.

COOLEY, C. H. Human nature and social order. New York: Scribner, 1924.

DAI, X. D. Intercultural Personhood and Identity Negotiation. China Media Research, v. 5, n. 2, p. 1-12, 2009.

ERIKSON, E. Identity and identity diffusion. In: GORDON, C.; GERGEN, K. (Eds.). The self in social interaction. New York: Wiley, 1968.

GEERTZ, C. Uma descrição densa: por uma teoria interpretativa da cultura. In: Rio de Janeiro: LTC, 1989. . A interpretação das culturas.

GRUSHINA, Y. Cultural adaptation research: a historical perspective and emerging trends in sojourner studies. Trabalho apresentado no encontro anual da International Communication Association, New York, EUA, 2009. Disponível em: http://www.allacademic.com/meta/p13903_index.html. Acessado em: 07 de Fevereiro de 2011.

GULLAHORN, J.; GULLAHORN, J. E. An extension of the U-curve hypothesis. Journal of Social Issues, v. 14, p. 33-47, 1963.

HASLBERGER, A. The complexities of expatriate adaptation. Human Resource Management Review, v. 15, n. 2, 160-180, 2005.

JOLY, A. Alteridade: ser executivo no exterior. In: CHANLAT, J.F. (Coord.). O indivíduo na organização: dimensões esquecidas. São Paulo, Atlas, 1996. 
JOVCHELOVITCH, S. Re(des)cobrindo o outro: para um entendimento da alteridade na teoria das representações sociais. In: ARRUDA, A. (Org). Representando a alteridade. Rio de Janeiro, Vozes, 1998.

KIM, Y. Y. Cross-cultural adaptation: An integrative theory. In: WISEMAN, R. L. (Ed.). Intercultural communication theory. Thousand Oaks, CA: Sage, 1995.

LYSGAARD, S. Adjustment in a foreign society: Norwegian Fulbright grantees visiting the United States. International Social Science Bulletin, v. 7, p. 45-51, 1995.

MACHADO, H. V.; HERNANDES, C. A. Alteridade, expatriação e trabalho: implicações para a gestão organizacional. RAC - Revista de Administração Contemporânea, v. 8, n. 3, p. 53-73, 2004.

OBERG, K. Culture Shock. Texto apresentado no Clube de Mulheres do Rio de Janeiro, Brasil, 1954. Disponível em: http://www.youblisher.com/p/53061-Please-Add-a-Title/. Acessado em 07 de Fevereiro de 2011.

ROSENBERG, M.; KAPLAN, H. Social psychology of the self-concept. Arlington Heights, IL, Harlan Davidson, 1982.

SÁNCHEZ, J. I.; SPECTOR, P. E.; COOPER, C. L. Adapting to a boundaryless world: A developmental expatriate model. Academy of Management Executive, v. 14, n. 2, p. 96-107, 2000.

SHAFFER, M. A.; HARRISON, D. A.; GILLEY, K. M. Dimensions, determinants, and differences in the expatriate adjustment process. Journal of International Business Studies, v. 30, n. 3, p. 557-581, 1999.

SUSSMAN, N. M. Testing the cultural identity model of the cultural transition cycle: Sojourners return home. International Journal of Intercultural Relations, v. 26, n. 4, p. 391-408, 2002.

WANG, X. Expatriate adjustment from a social network perspective: theoretical examination and a conceptual model. International Journal of Cross Cultural Management, v. 2, n. 3, p. 321-337, 2002.

WARD, C.; OKURA, Y.; KENNEDY, A.; KOJIMA, T. The U-curve on trial: a longitudinal study of psychological and sociocultural adjustment during cross-cultural transition. International Journal of Intercultural Relations, v. 22, n. 3, p. 277-291, 1998.

ZAHARNA, R. S. Self-Shock: the double binding challenge of identity. International Journal of Intercultural Relations, v. 13, p. 501-525, 1989. 